\title{
COMUNICAÇÃO TERAPÊUTICA EM ENFERMAGEM REVELADA NOS DEPOIMENTOS DE PACIENTES INTERNADOS EM CENTRO DE TERAPIA INTENSIVA*
}

\author{
THERAPEUTIC COMMUNICATION IN REVEALED NURSING IN THE DEPOSITIONS OF INTERNED PATIENTS \\ IN CENTER OF INTENSIVE THERAPY
}

\section{COMUNICACIÓN TERAPÉUTICA EN ENFERMERÍA REVELADO EN LOS DEPOIMENTOS DE PACIENTES INTERNADOS EN CENTRO DE TERAPIA INTENSIVA}

\section{Poliéria Santos de Oliveira ${ }^{1}$ Maria Miriam Lima da Nóbrega ${ }^{2}$ Ana Tereza Medeiros Cavalcanti da Silva ${ }^{3}$ Maria de Oliveira Ferreira Filha ${ }^{4}$}

RESUMO: Estudo qualitativo, com pacientes internados em um Centro de Terapia Intensiva de uma instituição pública de João Pessoa, com o objetivo de verificar o significado da comunicação em enfermagem. Os dados foram obtidos mediante entrevistas e analisados através das categorias da comunicação terapêutica da grade de análise dos grupos de expressão, clarificação e validação. Entre as técnicas de comunicação empregadas pelos enfermeiros encontramos: usar terapeuticamente o silêncio, ouvir reflexivamente, verbalizar a aceitação, uso terapêutico do humor. A partir dos resultados pode-se inferir que as técnicas de comunicação são um meio de promover o relacionamento terapêutico, necessário a uma assistência de enfermagem de boa qualidade, por permitir a identificação das necessidades dos pacientes.

PALAVRAS CHAVE: Comunicação; Cuidados de enfermagem; Cuidados Intensivos.

ABSTRACT: This is a qualitative study with patients in the Intensive Care Center of a Public Hospital in João Pessoa (PB). The aim of the study was to verify the meaning of the communication in Nursing. The data were obtained from interviews and analyzed by the therapeutic communication categories of the expression, clarification and validation group analysis bars. Among the communication techniques used by Nurses team, we found to use therapeutic the silence, to hear reflexively, to verbalize the acceptance, therapeutic use of the humor. The results allow inferring us that the communication techniques are a way for therapeutic relationship promoting, which is necessary to a better quality assistance care, allowing, thus, the patients' needs identification.

KEY WORDS: Communication; Nursing care; Intensive Care.

RESUMEN: Esto es un estudio cualitativo con los pacientes de uno Centro de Cuidados Intensivos de un Hospital Publico de la ciudad de João Pessoa (PB). El objetivo del estudio fuera verificar el significado de la comunicación en enfermería. Los datos fueran obtenidos por medio de entrevistas y analizado por las categorías de comunicación terapéuticas de la grade de análisis del grupo de la expresión, de la clarificación y de la validación. Entre las técnicas de la comunicación usadas por el equipo de enfermería, encontramos: utilizar terapéuticamente el silencio, oír reflexivamente, verbalizar la aceptación, uso terapéutico del humor. Los resultados permiten el deducir que las técnicas de la comunicación son una manera para la promoción de la relación terapéutica, que es necesaria a un cuidado de enfermería de mejor calidad, permitiendo, así, la identificación de las necesidades de los pacientes.

PALABRAS CLAVES: Comunicación; Atención de Enfermería; Cuidados Intensivos.

\section{INTRODUÇÃO}

A comunicação representa uma troca de informação e compreensão entre as pessoas, com objetivo de transmitir fatos, pensamentos e valores. É um processo humano de emissão e recepção de mensagens, no qual existem dois meios de transmissão de mensagens: o verbal e não-verbal. 0 verbal contempla a linguagem falada e escrita, enquanto os gestos, as expressões corporais e o toque fazem parte da forma não-verbal.

A comunicação verbal é a base da comunicação cotidiana, através da qual exercitamos a capacidade de atribuir o significado das coisas que não são ditas explicitamente, enriquecendo a compreensão da realidade. $O$ conhecimento dos mecanismos de comunicação pelos profissionais de saúde, em especial os enfermeiros, facilita o desempenho de suas funções, bem como, melhora o relacionamento entre os sujeitos envolvidos na assistência à saúde (DOBRO et al., 1998).

A comunicação precisa ser considerada dentro do seu contexto de ocorrência, ou seja: onde, como e quando ela ocorre. Caso contrário, seu sentido pode ser prejudicado, razão pela qual, na assistência à saúde ela precisa ser planejada para cada interação e adequada a cada paciente. Nesse sentido, ela é parte das atividades do enfermeiro, porque é empregada em situações como, na entrevista, no exame físico, no planejamento da assistência, nas anotações dos prontuários e nas orientações aos indivíduos, famílias e comunidades. Disso decorre a importância de o 
OLIVEIRA, Poliéria Santos de; NÓBREGA, Maria Miriam Lima da; SILVA, Ana Tereza da; FILHA, Maria de Oliveira Ferreira - 55 Comunicação terapêutica em enfermagem revelada nos depoimentos de pacientes internados em centro de terapia intensiva. Revista Eletrônica de Enfermagem, v. 07, n. 01, p. 54 - 63, 2005. Disponível em www.fen.ufg.br/revista.htm

enfermeiro ter consciência da forma como se dá o processo de comunicação e dos elementos que o compõe.

A comunicação enfermeiro-paciente é denominada comunicação terapêutica, porque tem a finalidade de identificar e atender as necessidades de saúde do paciente e contribuir para melhorar a prática de enfermagem, ao criar oportunidades de aprendizagem e despertar nos pacientes sentimentos de confiança, permitindo que eles se sintam satisfeitos e seguros (STEFANELLI, 1993; ATKINSON \& MURRAY, 1989).

Um dos objetivos da assistência de enfermagem é levar o paciente a participar dos esquemas terapêuticos. Esta participação depende dos processos de comunicação, a partir dos quais se estabelecem as relações de confiança necessárias para o paciente diminuir o medo, a ansiedade e permitir, à pessoa fragilizada pela doença, lutar por seu restabelecimento com dignidade. Nesse sentido, os enfermeiros intensivista além da experiência no uso de tecnologias, e do suporte psicossocial, deve estar atenta ao processo de comunicação para que o paciente possa suportar os efeitos da hospitalização, manter a percepção de si próprio e da sua realidade (HUDAK \& GALLO, 1997).

Por ocasião de estagio curricular, no hospital, observei a importância da Comunicação Terapêutica, na UTI. Os pacientes, por perderem o contato com o ambiente familiar, tornam-se mais sensíveis, necessitando tanto de atendimento de alta complexidade, como do relacionamento terapêutico, especialmente com a equipe de enfermagem, responsável pelos cuidados do paciente hospitalizado, diuturnamente, em uma relação que tem base na comunicação.

A reflexão sobre essas situações de Tratamentos Intensivos motivou alguns questionamentos, entre os quais, como ocorre a comunicação enfermeira-paciente na UTI, e, orientou a formulação do seguinte objetivo do estudo: identificar, através do discurso dos pacientes internados no CTI, as técnicas mais utilizadas pela equipe de enfermagem na comunicação com o paciente.

\section{REVISÃO DE LITERATURA}

A comunicação é o meio através do qual, pessoas interagem umas com as outras. O homem utiliza a comunicação nas ações do cotidiano e é por meio dela que partilha, com os demais, suas idéias. Nessa partilha, ele está sujeito a receber aprovação e desaprovação das outras pessoas, e isto acaba por determinar sua sensação de segurança e satisfação e seu ajustamento no ambiente que o rodeia (STEFANELLI, 1993).

A comunicação é um ato intrínseco ao existir humano, consistindo na capacidade de trocar idéias, de dialogar, de conversar visando ao relacionamento humano (BITTES JUNIOR \& MATHEUS, 1996). Conforme ATKINSON \& MURRAY (1989), a comunicação pode ser definida de forma simples com "significado compartilhado", ou seja, quando ocorre compreensão da mensagem que foi enviada entre o emissor e o receptor. Embora as pessoas compartilhem das palavras encontradas no dicionário, a forma de usá-las para transmitir significado é única.

Para STEFANELLI (1993), a comunicação deve ser entendida como um processo de compreender, compartilhar mensagens enviadas e recebidas, sendo que essas mensagens e o modo como se dá seu intercâmbio exerce influencia no comportamento das pessoas e provocam mudanças no ambiente em que a comunicação é efetivada.

Para melhor desenvolvermos a comunicação é preciso conhecer os componentes desse processo que são: o emissor ou remetente (aquele que emite a mensagem), receptor (aquele que recebe a mensagem) e a mensagem (informação ou emoção passada do emissor para receptor). O remetente é quem inicia a comunicação. A mensagem é a informação enviada, que para ser efetiva é preciso ser clara e organizada de modo familiar ao receptor, podendo ser composta por informações verbais ou não verbais; o receptor é a pessoa para quem a mensagem é enviada. Para a comunicação ser efetiva a mensagem do emissor deve ser um estímulo para o receptor e este deve decodificá-la e respondê-la (POTTER \& PERRY, 2002).

BITTES JÚNIOR \& MATHEUS (1996) afirmam que no relacionamento entre enfermeira e paciente, o enfermeiro pode assumir tanto o papel de emissor como de receptor, significando a necessidade de se enviar mensagens que o paciente entenda como também entender as mensagens recebidas.

Segundo SILVA (1996), a comunicação é um ato criativo, não existe apenas um agente emissor ou receptor, mas uma troca entre as pessoas que formam um sistema de interação e reação, isto é, um processo recíproco que provoca mudanças na forma de sentir, pensar e atuar dos envolvidos.

A comunicação envolve todos os meios utilizados por uma pessoa para afetar o outro. Para transmitirmos uma mensagem podemos utilizar a forma verbal que esta associada à linguagem falada e escrita, como também podemos nos comunicar de forma não-verbal através das expressões, gestos e o toque. Ainda existe a comunicação para verbal que diz respeito ao tom de voz, ritmo, períodos de silencio e entonação que damos as palavras. STEFANELLI (1993) afirma que, a comunicação verbal ocorre por meio da linguagem e é através dela que expomos nossas idéias, partilhamos experiências com as pessoas, e validamos o significado simbólico da percepção sobre o assunto e o lugar que ocupa nela. A comunicação não-verbal pode ser definida como toda informação obtida por meio de gesto, postura, expressões faciais e corporais, pela distância mantida entre os indivíduos, ou seja, a mensagem transmitida sem o uso de palavras (SILVA, 1996).

Dentre as formas de comunicação não verbal os gestos passam mensagens mais significativas do que as palavras. A forma como uma pessoa se mantém ereta, a postura e a marcha refletem emoções, autoconceito e bem-estar físico, enquanto uma postura 
OLIVEIRA, Poliéria Santos de; NÓBREGA, Maria Miriam Lima da; SILVA, Ana Tereza da; FILHA, Maria de Oliveira Ferreira - 56 Comunicação terapêutica em enfermagem revelada nos depoimentos de pacientes internados em centro de terapia intensiva. Revista Eletrônica de Enfermagem, v. 07, n. 01, p. 54 - 63, 2005. Disponível em www.fen.ufg.br/revista.htm

arqueada, curvada e uma marcha lenta podem indicar depressão ou mal estar (POTTER \& PERRY, 2002).

Conforme BITTES JÚNIOR \& MATHEUS (1996), o corpo comunica-se de várias formas através dos seus movimentos, a isto denominamos de cinésica. A forma de comunicação chamada proxêmica refere-se a distancia mantida durante a comunicação e define o tipo de comunicação que queremos desenvolver.

O toque, uma forma de comunicação não verbal, deve estar presente em toda assistência; este não deve ser condicionado a realização de procedimentos técnicos científicos; mas devem ter a finalidade de demonstrar carinho, empatia, segurança e proximidade em relação ao paciente (SILVA, 1996).

Segundo DOBRO et al (1998) existem fatores que interferem na percepção do verbal e do nãoverbal, tais como, a) Nossas expectativas e emoções: quando alegres, interessados, ficamos mais susceptíveis a leitura do não-verbal. Tristeza, contrariedade, raiva, dificultam essa tarefa; b) Estereótipo e experiências anteriores diminuem a visão do contexto do indivíduo e acionam os nossos mecanismos de proteção; c) A dificuldade de reconhecer os sinais que expressam o não-verbal; d) O pouco conhecimento do indivíduo que está emitindo seu significado; e) Pouco tempo utilizado para o reconhecimento do estímulo que acaba por empobrecer nossa percepção; f) Limitações físicas relacionadas aos órgãos dos sentidos e alterações metabólicas como dor, cansaço, que limitam a identificação do não-verbal; g) Os ruídos funcionam como interferência quando se tenta estabelecer uma interação; e h) A não motivação nos impede de desenvolvermos habilidades para lidarmos com o nãoverbal.

A comunicação tem várias funções. Segundo STEFANELLI (1993), podemos citar a de investigação (busca de dados sobre o paciente); informação (envio de mensagens entre emissor e receptor ou vice e versa); persuasão (levar o receptor a mudança de comportamento, sobre o qual não havia pensado antes); e entretenimento (mistura de persuasão com informação é utilizada para diminuir a ansiedade e favorecer a interação entre emissor e receptor).

No processo de comunicação devemos estar atentos a todos os elementos que possam vir a impedir que esta ocorra efetivamente, a estes aspectos denominamos de barreiras da comunicação. Para BITTES JÚNIOR \& MATHEUS (1996), estas barreiras pedem ser: falta da capacidade de concentração, a pressuposição de entendimento, ausência de significação comum, influencia de mecanismo inconsciente limitação do emissor/receptor, falta da habilidade para ouvir, sentir e compreender a mensagem do outro.

Conforme STEFANELLI (1993), os profissionais da área de saúde que são realmente preocupados com o ser humano procuram desenvolver meios, instrumentos, técnicas, habilidades, capacidade e competência para oferecer ao mesmo a oportunidade de uma existência mais digna, mais compreensiva e menos solitária.
Nos hospitais existe uma constante troca de informações e experiências entre as pessoas. Portanto, se houver um domínio da comunicação como instrumento facilitador da assistência, as necessidades dos pacientes serão mais facilmente observadas, compreendidas e atendidas pelos profissionais de saúde (DOBRO et al, 1998).

De acordo com STEFANELLI (1993), ao considerarmos que não podemos existir sem nos comunicar, e que existimos como pessoa em frente à outra, concluímos que nossa vida é um contínuo comunicar. Dessa forma como enfermeiras, devemos tornar a nossa comunicação verbal e não verbal, a mais útil possível para o bem estar daqueles que estão internados e necessitam de nossos cuidados.

Quando uma pessoa passa pelo processo de hospitalização, segundo SINNO (1987) ocorre a transposição da situação de "normalidade", antes garantida pela condição de saúde, para de dependência dos profissionais na resolução de seus problemas o que constitui, por si, elemento de desconforto e insegurança. Quando usamos conscientemente as técnicas de comunicação em todo o processo de relacionamento com o paciente buscamos compreender e identificar suas necessidades. Neste contexto percebemos a importância de se estabelecer um relacionamento terapêutico conseguido através da utilização da comunicação terapêutica.

\section{Comunicação Terapêutica na Enfermagem}

A comunicação terapêutica é a habilidade de um profissional em ajudar as pessoas a enfrentarem seus problemas, relacionarem-se com os demais, ajustarem o que não pode ser mudado e enfrentarem os bloqueios à auto-realização (SILVA, 1996).

RODRIGUES (1991, 1995, apud NEGRINI \& RODRIGUES, 2000) relata que a comunicação terapêutica é vista como um processo por meio do qual uma pessoa tenta conscientemente ajudar a outra a aumentar sua capacidade adaptativa.

A comunicação terapêutica permite uma interação entre enfermeira e paciente, e proporciona a oportunidade de se conseguir um relacionamento humano que atinja os objetivos da assistência. $\mathrm{O}$ uso da comunicação terapêutica pelo enfermeiro aumenta a aceitação e a compreensão do paciente quanto à realização dos procedimentos, diminuindo a necessidade (POTTER \& PERRY, 2002).

Dessa forma a comunicação é de suma importância na prática de enfermagem, pois permite ao profissional estabelecer um relacionamento de trabalho com os pacientes, ajudando-os a suprir suas necessidades em relação à saúde (POTTER \& PERRY, 2002). As mesmas autoras assinalam que através da comunicação são criadas condições, para que o profissional de enfermagem efetive mudanças, no intento de promover o bem-estar do paciente.

Assim, desenvolver as habilidades de comunicação é de fundamental importância para os profissionais da área de saúde, em especial os enfermeiros, que devem conhecer o significado das 
mensagens enviadas pelo paciente para então elaborar um plano assistencial adequado para atender as necessidades do mesmo.

Para SILVA (1996), a comunicação adequada e efetiva é aquela que tenta diminuir conflitos, malentendidos para atingir objetivos definidos na solução de problemas detectados em situações de interação com os pacientes. STEFANELLI (1993) completa esse pensamento colocando que é através de um relacionamento efetivo com o paciente, que o enfermeiro oferece-Ihe apoio, conforto, informação e desperta seu sentimento de confiança e auto-estima.

Segundo NEGRINI \& RODRIGUES (2000), 0 relacionamento enfermeira-paciente é a forma eficaz, que o profissional tem para ajudar seu paciente com dificuldades, na medida em que possibilita conhecê-lo como pessoa e identificar suas necessidades.

O essencial para que os enfermeiros desenvolvam uma comunicação eficaz é estabelecer um relacionamento empático. O intensivista constrói esta empatia através de encontros que, mesmo sendo rápidos, devem ser feitos com honestidade e sensibilidade para identificar as necessidades de cada paciente. É necessário também, que o enfermeiro considere a individualidade, os valores e crenças dos pacientes, e utilize uma linguagem clara, de acordo com o nível de instrução dos mesmos, permitindo assim uma avaliação mais fidedigna de suas necessidades.

Os equipamentos, o grande número de profissionais trabalhando no CTI, os ruídos, os sons, as emergências, a agitação e o não entendimento sobre estado de saúde dos demais fazem com que o paciente venha a sentir sentimentos de medo, insegurança e isolamento, prejudicando sua tranqüilidade e, conseqüentemente, levando-os a necessitarem de um maior uso de tranqüilizantes.

Segundo SANTOS \& LEMES (2001), os pacientes lúcidos e conscientes, internados em um $\mathrm{CTI}$, percebem tudo ao seu redor, bem como toda assistência a ele prestada pela intensivista. O mesmo autor afirma que os enfermeiros podem influenciar de maneira positiva ou negativa a compreensão do paciente sobre sua hospitalização dependendo do modo como estes se relacionam.

O relacionamento enfermeira-paciente é um meio eficaz do qual o profissional pode recorrer para ajudar seu paciente em suas dificuldades, na medida em que permite conhecê-lo como pessoa e identificar suas necessidades (NEGRINI \& RODRIGUES, 2000).

De acordo com TRAVELBEE (1972 apud GATTAS, 1984), a interação enfermeira-paciente é singular, ocorre durante um período particular na vida de ambos e, portanto, não pode ser repetida ou imitada. Uma característica dessa interação é que cada encontro é único e original, mas, também, representa o começo ou o ponto de partida das interações subseqüentes.

Os profissionais de saúde não devem esquecer que suas mensagens não são interpretadas apenas pelo que fala, mas também pela forma como se comportam. Dessa forma podemos tornar nossa comunicação mais efetiva ao tomar consciência da importância da linguagem corporal, principalmente no que diz respeito à proximidade, postura, toque e o contato visual (SILVA, 1996).

O toque pela Enfermagem pode ser mais útil em situações nas quais as pessoas apresentam medo, ansiedade ou depressão. Também pode ser benéfico em pacientes que necessitam de encorajamento ou de acalento, que tem dificuldade em verbalizar necessidade, em desorientados, não-responsivos ou em fase terminal de doença (HUDAK \& GALLO, 1997).

Nesta perspectiva BITTES JÚNIOR \& MATTHEUS (1996) afirmam que, a comunicação em enfermagem pode ser vista como uma necessidade humana básica, uma competência que o enfermeiro deve utilizar para desenvolver e aperfeiçoar o saberfazer profissional. Desse modo a comunicação deve ser reconhecida pelos enfermeiros como arte $\mathrm{e}$ responsabilidade, para que melhor possam assistir o paciente.

STEFANELLI (1993) acrescenta que a comunicação deve ser considerada como uma competência interpessoal a ser conquistada pelo enfermeiro, que empregada de modo terapêutico, possibilitará o atendimento do paciente em todas as suas dimensões.

$\mathrm{Na}$ Enfermagem a comunicação está presente em todas as suas ações, influenciando diretamente a qualidade da assistência prestada aos que necessitam de seus cuidados e a interação enfermeira paciente. Neste contexto, BARCELLOS \& CAMPONOGARA (2001) afirmam que a interação enfermeira paciente é única, nenhuma outra estrutura de interação pode oferecer ao paciente uma fonte mais potente de apoio: um fundamento profissional instruído e uma aceitação humana, atenciosa como uma pessoa de valor e dignidade.

Os enfermeiros não devem esquecer na sua prática, que a comunicação verbal precisa estar associada à comunicação não-verbal, confirmando o expresso verbalmente pela pessoa. Dessa maneira pode-se dizer que há coerência entre ambas, demonstrando uma efetividade na comunicação.

Conforme POTTER \& PERRY (2002), o enfermeiro no intento de auxiliar o paciente, deve estar ciente de seus valores, sentimentos e atitudes em relação a este, aprendendo a comunicar-se com ele de modo adequado, já que, aquilo que o profissional sente ou pensa em relação ao individuo será transmitido não verbalmente. Isso significa que o enfermeiro não deve negar qualquer sentimento negativo que possa ter em relação a um paciente, dominando, porém, a maneira de expressar seus sentimentos em relação ao mesmo, não o condenando ou censurando.

$\mathrm{Na}$ prática da enfermagem, a comunicação verbal, expressa através da linguagem escrita focalizase nas funções de fazer relatórios e registros. Esses registros devem conter vocabulário científico, precisão e exatidão ao descrever um acontecimento relativo ao paciente, para permitir uma comunicação efetiva entre os membros das equipes de enfermagem e saúde. As anotações de enfermagem são julgadas como 
importantes porque são documentos que auxiliam no planejamento, continuidade e avaliação do paciente.

A comunicação como processo colabora na qualidade das relações de trabalho seja com a equipe de saúde, seja no registro das atividades de enfermagem, na assistência ao paciente, família e comunidade, além de evitar que barreiras de comunicação comprometam a eficiência do processo de cuidar do próprio exercício de enfermagem (BITTES JUNIOR \& MATHEUS, 1996).

Nas etapas do processo de enfermagem, o profissional utiliza técnicas de comunicação, pois, está coletando, assimilando e transmitindo informações constantemente. Esse processo fornece uma base de elementos confiável para a prestação de uma assistência de boa qualidade, mas poderá ser interrompida se o profissional não utilizarem a comunicação terapêutica (POTTER \& PERRY, 2002).

No desenvolvimento do processo terapêutico existem técnicas de comunicação terapêutica que facilitam a interação enfermeira-paciente. Para STEFANELLI (1993), as técnicas não existem para serem usadas mecanicamente. Ao utilizá-las o enfermeiro deve considerar cada uma delas particularmente para cada situação específica. O enfermeiro, por interagir com o paciente com uma maior freqüência do que os demais profissionais da área de saúde, precisa estar mais atenta ao emprego das técnicas de comunicação terapêutica como facilitadora no processo de interação com o paciente. De acordo ainda com mesma autora as técnicas de comunicação podem ser classificadas em três grupos de expressão, de clarificação e de validação.

No grupo de expressão estão organizadas as técnicas que ajudam à descrição da experiência e a expressão de pensamentos e sentimentos sobre ela. Nesse grupo encontram-se as seguintes técnicas: usar terapeuticamente o silêncio; ouvir reflexivamente; verbalizar aceitação; verbalizar interesse; usar frases incompletas; repetir as últimas palavras ditas pelo paciente; fazer pergunta; desenvolver a pergunta feita; usar frases descritivas; manter o paciente no mesmo assunto; permitir ao paciente que escolha o assunto; colocar em foco a idéia principal; verbalizar dúvidas; dizer não; estimular expressão de sentimentos subjacentes; e o uso terapêutico do humor.

No grupo de clarificação estão às técnicas que ajudam a esclarecer o que for expresso pelo paciente, entre elas podemos citar: estimular comparações; solicitar que esclareça termos comuns; solicitar ao paciente que precise o agente de ação; e descrever os eventos em seqüência lógica.

No grupo de validação as técnicas permitem a existência de significação comum do que é expresso, e são apresentadas como: repetir a mensagem do paciente; pedir ao paciente para repetir o que foi dito; e sumarizar o conteúdo da interação.

As técnicas de comunicação terapêutica são um instrumento que contribui para a excelência da assistência de enfermagem e permite o desenvolvimento de um relacionamento terapêutico entre enfermeira-paciente.Com este relacionamento o enfermeiro permite ao paciente a expressão de percepções, pensamentos e sentimentos pelo paciente e relacioná-los com ações observadas e relatadas (STUART \& LARAIA, 2002).

\section{CONSIDERAÇÕES METODOLÓGICAS}

A comunicação está diretamente relacionada à qualidade da assistência prestada ao paciente. No intuito de investigar o significado da comunicação para o paciente de UTI, e de que modo ela influencia o relacionamento enfermeira-paciente, foi desenvolvido este estudo, realizado no Centro de Terapia Intensiva do Hospital Universitário Lauro Wanderley, uma instituição pública federal, hospital-escola da Universidade Federal da Paraíba - UFPB, localizada na cidade de João Pessoa - Paraíba. A escolha do local deve-se ao fato de ser campo de estágio prático para os alunos do Curso de Graduação em Enfermagem desta Universidade.

O Centro de Terapia Intensiva é uma unidade de internação, com disponibilidade de 06 leitos, destinados aos pacientes provenientes da Clinica Médica, Clínica Cirúrgica e do Sistema de Pronto Atendimento - SPA. A equipe de enfermagem do serviço é composta por 11 enfermeiros, um dos quais atua na chefia; 29 técnicos de enfermagem, 01 auxiliar administrativo e 04 auxiliares operacionais. O projeto foi autorizado pelo Comitê de Ética em Pesquisa e à autorização do HULW/UFPB observando os aspectos éticos e legais da pesquisa envolvendo seres humanos da Resolução 196 de 1996 do Conselho Nacional de Saúde.

Os sujeitos da investigação foram os pacientes conscientes e orientados, internados no CTI no momento da coleta de dados, ocorrida no período de julho a setembro de 2004. Os participantes foram informados sobre o objetivo da pesquisa, e sobre os direitos ao anonimato, a autonomia de participar ou não do estudo, bem como de desistir da participação a qualquer momento da pesquisa, e, assinaram o Termo de Consentimento Livre e Esclarecido.

Fizeram parte do estudo, 06 (seis) pacientes do sexo feminino e 02 (dois) do sexo masculino. No que diz respeito ao estado civil, 02 (dois) sujeitos eram solteiros, 03 (três) mantinham união estável, 03 (três) eram casados. No que se refere ao grau de instrução, apenas 01 (um) sujeito tinha o ensino médio completo. Os demais participantes da amostra tinham o primeiro grau incompleto.

Os dados foram coletados através da técnica de entrevista, por meio de um roteiro de entrevista semiestruturado, para obtenção de dados de caracterização da amostra e respostas para os questionamentos. A análise dos dados foi desenvolvida no enfoque qualitativo buscando a identificação dos sujeitos entrevistados com as categorias da comunicação terapêutica da grade de análise dos grupos de expressão, clarificação e validação. Os resultados foram analisados com base na literatura pertinente ao tema e apresentados de forma descritiva. 


\section{ANÁLISE E DISCUSSÃO DOS RESULTADOS}

As técnicas da comunicação terapêutica ${ }^{(3)}$ são guias a serem usados em situações interpessoais com o paciente de modo individual, com linguagem acessível, devendo ter a mesma significação para todos os participantes. Nessa abordagem, as técnicas estão organizadas em três grupos: Expressão, Clarificação e Validação, formando a grade de análise das técnicas de comunicação terapêutica do estudo (STEFANELLI, 1993).

No grupo de expressão estão as técnicas que utilizamos no início do relacionamento terapêutico, pois, é necessário que as pessoas se conheçam e estabeleçam um clima de confiança entre elas (STEFANELLI, 1993). Faz parte desse grupo 15 técnicas de comunicação, das quais algumas não foram identificadas nos discursos dos pacientes, a saber: verbalizar interesse; usar frases incompletas; repetir as últimas palavras ditas pelo paciente; manter o paciente no mesmo assunto; permitir ao paciente que escolha o assunto; colocar em foco a idéia principal; verbalizar dúvidas; dizer não; e estimular expressão de sentimentos subjacentes.

As técnicas do grupo de expressão encontradas foram:

\section{- OUVIR REFLEXIVAMENTE}

Ouvir reflexivamente é uma das técnicas de comunicação terapêutica das mais efetivas, do que decorre seu caráter de instrumento essencial para que o enfermeiro estabeleça o relacionamento terapêutico. KRON \& GRAY (1994) afirmam que ouvir é um dos principais meios através do qual obtemos informações, e quando deixamos de ouvir renunciamos a um dos objetivos da comunicação, o de ficar sabendo sobre a outra pessoa para tentar compreendê-la. Neste estudo, observamos a adoção dessa técnica nos seguintes depoimentos sobre o enfermeiro:

\section{"Ainda tinha paciência para ficar me ouvindo" (Sujeito 06) \\ "Ah, elas gostavam de escutar eu contando minhas doidice, ficava me escutando e não perguntava nada“. (Sujeito 07) \\ "Quando ela tinha paciência de me escutar falando sobre minha vida" (Sujeito 01) \\ "Elas tinham interesse de me escutar falar, porque só sai de lá quando eu terminava de falar" (Sujeito 08)}

Os depoimentos revelam que a equipe de enfermagem do CTI utiliza a técnica, ouvir reflexivamente, como forma de demonstrar interesse pelo paciente e estimular a expressão dos seus sentimentos. Merece ser ressaltado que ouvir é um método não-verbal de comunicação, através do qual transmitimos ao paciente que ele é aceito e respeitado como ser humano, ou seja, que ele é reconhecido pelo enfermeiro como um sujeito, tendo importância e significação à relação entre eles. A técnica em análise permite também uma melhor percepção dos sinais da comunicação não-verbal emitidos pelo paciente.

STEFANELLI (1993) menciona que para ouvir o paciente devemos estar atentas para não julgar o conteúdo do pensamento expresso. Direcionamos toda nossa atenção ao paciente, pensando reflexivamente sobre o que ele diz para podermos compreender o significado do que está sendo dito. SILVA (1996) completa esse pensamento quando afirma que, para ouvirmos os outros precisamos aprender a controlar nossos sentimentos e preconceitos para demonstrarmos interesse no que está sendo comunicado.

\section{- VerbalizAR ACEITAÇÃo}

A aceitação é uma das necessidades humanas básicas, considerada pela enfermagem porque, para sentir-se seguro para falar, o paciente precisa sentir-se aceito (STEFANELLI, 1993). Para que esta aceitação seja genuína o enfermeiro precisa perceber o paciente como pessoa, só assim, este experimentará por meio de sentimento empático, a sensação de ser aceito. Verificamos o emprego desta técnica no texto que afirma a preocupação do enfermeiro com o paciente:

\section{"Aí elas diziam que não, que elas queriam o melhor pra mim". (Sujeito 06)}

Apesar de ser essencial, no relacionamento terapêutico, a técnica de verbalização da aceitação que informa o reconhecimento da aceitação, pelo paciente, só foi identificada em um depoimento. Isso demonstra que muitas vezes os enfermeiros enfatizam mais a assistência às necessidades físicas, do que às necessidades emocionais dos pacientes. Uma provável razão para este fato pode ser atribuída ao estresse vivenciado pelas os enfermeiros no CTI, que as impede de perceber a importância do paciente sentir-se aceito pela equipe que está responsável pelos seus cuidados. Aceitar o cliente não significa concordar com todas as suas manifestações de comportamento e sim promover a mudança necessária para melhorar seu nível de saúde (POTTER \& PERRY, 2002).

A ansiedade e a dor sentidas pelo paciente durante sua internação podem comprometer a comunicação, afetando o relacionamento enfermeirapaciente, de modo que, demonstrar ou verbalizar aceitação por parte do enfermeiro, permite ao paciente percebê-la como pessoa em quem pode confiar. Isso faz com que ele se sinta seguro e confortável para expressar seus sentimentos, facilitando o estabelecimento do relacionamento terapêutico. Segundo DU GAS (1989), a aceitação consiste da capacidade de uma pessoa compreender o ponto de vista da outra respeitando o direito de cada um em ser diferente, significando, assim, ausência de julgamento.

\section{- USAR TERAPEUTICAMENTE O SILÊNCIO}

Essa é uma das técnicas mais difíceis de serem praticadas, uma vez que seu uso requer 
paciência do terapeuta. Contudo, a técnica transmite ao paciente a idéia de que o profissional está atento e pronto para ouvi-lo, demonstrando respeito pela sua intimidade, bem como, podendo demonstrar, também, que o silencio é uma forma aceitável de conforto (STEFANELLI, 1993).O seu emprego foi encontrado nos seguintes depoimentos:

"Quando eu tava triste ela vinha e ficava
perto de mim" (Sujeito 07)
"Tinha algumas vezes que ela ficava calada
perto de mim, aí eu puxava assunto". (Sujeito
06)
"Quando eu tava triste ela vinha e ficava
perto de mim calada". (Sujeito 03)

Os depoimentos apresentados manifestam o discurso sobre a percepção do paciente acerca da importância do silêncio, empregado pelo enfermeiro como instrumento de comunicação. Verifica-se que ao colocar em prática essa técnica o enfermeiro estimula o paciente a iniciar uma conversa, além de transmitir apoio e compreensão pelo seu estado. Ao empregar o silêncio devemos estar atentos à comunicação nãoverbal, aos sentimentos do paciente como, o medo, a ansiedade e a tristeza.

Quando se está em silêncio, próximo ao paciente, a postura mantida pelos enfermeiros, suas expressões faciais e manifestações assumidas, podem transparecer impaciência. Por isso, ao utilizar esta técnica, o enfermeiro deve estar livre de preocupações e sentimentos negativos, uma vez que a presença do enfermeiro pode dizer ao paciente que ele não está sozinho e que esta sendo assistido (SMELTZER \& BARE, 2000).

\section{- FAZER PERGUNTAS}

As perguntas são partes importantes no levantamento de dados. Para obtermos as respostas que precisamos devemos perguntar de maneira apropriada, determinando exatamente 0 que desejamos descobrir (KRON \& GRAY, 1994). O emprego dessa técnica de comunicação foi identificado nos depoimentos:

\section{"Eles gostam também de perguntar coisas sobre minha cidade, minha mãe". (Sujeito 04) "Perguntavam o que é que a senhora sente, o que a senhora quer?". (Sujeito 05) \\ "Elas perguntavam da doença, como eu tava".(Sujeito 06)}

Nos textos acima, observamos que ao utilizar a técnica de fazer perguntas, o enfermeiro obtém maiores informações acerca de sentimentos do paciente. Nesse sentido, a pergunta deve ser usada com propriedade, quando o enfermeiro deseja obter do paciente, informações específicas, e, quando a finalidade for estimular o paciente a dar continuidade ao assunto e esclarecer suas idéias.

Fazer inúmeras perguntas ao mesmo tempo pode resultar em fadiga física e emocional e tornar o paciente menos confiante e mais receoso das intenções do profissional. Os enfermeiros devem preferir o emprego de perguntas abertas, elas dão uma maior liberdade ao paciente para optar por uma resposta mais detalhada (ATKINSON \& MURRAY, 1989).

Além de permitir que o profissional avalie um maior número de fatores, a formulação de perguntas deve ser feita de maneira clara, simples, curta e objetiva, com ritmo e velocidade apropriados porque, só assim, transmitem a mensagem de modo adequado.

\section{- DEVOLVER A PERGUNTA FEITA}

Ao devolver ao paciente a pergunta feita por ele, o enfermeiro tenta mostrar-lhe que o ponto de vista dele é o mais importante (STEFANELLI, 1993). Encontramos seu emprego nos seguintes depoimentos:

"Perguntava as coisas sobre os filhos delas e ela perguntava sobre meu filho. " (Sujeito 07)

"O que ela acha do respeito ai ela perguntava o que eu acho." (Sujeito 08)

Nos textos acima, os pacientes manifestam os discursos sobre o emprego dessa técnica pelo enfermeiro para demonstrar seu interesse pelo paciente, deixando claro que seus valores são relevantes e, que, naquele momento, ele é o foco da atenção. A devolução da pergunta ajuda o enfermeiro a manter a conversação centrada no paciente e a obter dele informações acerca da pergunta. Desse modo, ao devolver a pergunta, o enfermeiro ajuda o paciente a desenvolver um raciocínio sobre o assunto e a entender melhor a necessidade que gerou a pergunta (SILVA, 1996).

Algumas perguntas são feitas à enfermeira na tentativa de obter maneiras de resolver problemas. Quando ela devolve a pergunta auxilia o paciente a explorar outras possibilidades de resolução, levando-o a ampliar aspectos relevantes a serem considerados na solução de seus problemas.

\section{- USAR FRASES DESCRITIVAS}

Ao explicar as rotinas da unidade, procedimentos de enfermagem, orientações, no desempenho da função de educadora em saúde, o enfermeiro faz uso de frases descritivas como técnica de comunicação (STEFANELLI, 1993). No estudo, essa técnica foi identificada nos seguintes depoimentos:

"Quando eu não entendia as coisas eu perguntava aí ela respondia direito, explicava até eu entender." (Sujeito 01)

"Ela dizia o que ia fazer comigo e explicava da doença." (Sujeito04)

"Quando me diziam o que estavam fazendo." (Sujeito 02) 
"O que eu procurava saber ela explicava." (Sujeito05)

Essa técnica identificada nos textos acima, foi utilizada pelo enfermeiro no intuito de esclarecer as dúvidas do paciente e explicar os procedimentos técnicos que iria realizar. O enfermeiro deve oferecer apenas informações necessárias para o paciente, deve falar pausadamente, com tom de voz adequado e com um vocabulário que corresponda ao nível cultural do paciente. A comunicação eficiente deve ser simples e direta. O uso de poucas palavras resultará em menos confusão. Para obtermos clareza devemos falar lentamente e pronunciando claramente as palavras (POTTER \& PERRY, 2002).

A ansiedade vivida pelo paciente durante sua hospitalização pode dificultar o entendimento de explicações longas, oferecidas pelo enfermeiro. Dessa forma, as explicações devem ser dadas de maneira clara, concisa e em um tom de voz audível. Quando a hospitalização ocorre no CTI, ambiente que emprega tecnologia avançada, essencial para salvar vidas, os sentimentos e expectativas do paciente se acentuam mais ainda devido ao medo da morte, razão pela qual devemos considerar de extrema relevância as explicações dadas ao paciente quando realizamos alguns procedimentos, ou quando são questionadas sobre a importância desses procedimentos.

O profissional de enfermagem deve reconhecer a ocasião adequada para explicações ou conversas com o paciente, esperando o momento certo, geralmente quando o paciente demonstra interesse. Durante a conversa, o enfermeiro não deve mudar de assunto rapidamente, porque isso bloqueia a comunicação e revela atitudes de desinteresse, incompatível com a responsabilidade do enfermeiro de instruir corretamente o paciente (SMELTZER \& BARE, 2000).

\section{- USO TERAPÊUTICO DO HUMOR}

O humor é uma habilidade vital da comunicação e um mecanismo que pode ajudar, pacientes e familiares, a aliviar sentimentos como medo, ansiedade, raiva e depressão (BELLERT, 1989, apud STEFANELLI, 1993) Nas entrevistas, esse elemento da comunicação manifestou-se nos depoimentos abaixo:

\footnotetext{
"Eles brincavam comigo e eu gostava. Eles sempre falavam coisas para eu ficar alegre " quando elas faziam brincadeira eu começava a rir e esquecia das coisas que tava sentindo." (Sujeito 04).

"Elas gostavam de tirar brincadeira e eu respondendo "eu gostava de conversar." (Sujeito 06). "quando eu tava triste ela vinha " conversando pra eu ficar alegre." (Sujeito 03).
}

Nos depoimentos percebemos que os enfermeiros fazem uso dessa técnica. A razão para o emprego do humor como terapêutica decorre da estimulação para liberação de substâncias que ajudam a controlar o humor. Essas situações, em momentos oportunos, fazem com que o paciente esqueça, por alguns momentos, que está em um ambiente fechado e estressante, o que é conseguido quando o paciente sorri.

$\mathrm{Na}$ utilização dessa técnica o enfermeiro precisa conhecer o paciente e a situação em que estão, devendo antes ter estabelecido um relacionamento terapêutico. O humor libera energia por meio de um comentário cômico sobre a imperfeição, podendo promover o discernimento, tornando conscientes os temas reprimidos que ajudam a resolver paradoxos, surtos de agressão e revelar novas opções (STUART \& LARAIA, 2002).

No grupo de clarificação, estão às técnicas que utilizamos para obter o significado explicito da mensagem. Ela ajuda ao paciente estabelecer prioridades (STEFANELLI, 1993). Nesse grupo existem quatro técnicas, dentre as quais, solicitar ao paciente que precise o agente de ação e descrever os eventos em seqüência lógica, que não foram identificadas nos depoimentos. As técnicas identificadas foram as seguintes :

\section{- ESTIMULAR COMPARAÇÕES}

Essa técnica ajuda o paciente a descobrir semelhanças e diferenças entre as experiências vividas por ele (STEFANELLI, 1993), conforme os depoimentos:

"Quando ela não entendia, eu fazia
comparações." (Sujeito 01).
"Quando ela não me entendia tinha que
comparar com algumas coisas para ela
entender." (Sujeito 06).
"Quando ela não entendia pedia pra eu
repetir comparando com alguma coisa. ".
(Sujeito 07).

Nos textos, encontramos o emprego dessa técnica com o intuito de compreender o que o paciente está expressando e entender as semelhanças com situações vividas anteriormente, cujos mecanismos de manejo foram utilizados para superá-las. Esta técnica ajuda o paciente a se expressar tentando entender o real significado de suas palavras.

Quando o enfermeiro estimula comparações com situações vividas, pelo paciente, facilita a descrição de seus pensamentos e sua participação no processo de recuperação. Ao comparar situações, ele pode avaliar a influencia das pessoas e do ambiente nas suas experiências, renovar a confiança em suas forças e até mesmo compreender o porquê dos problemas que vivencia (STEFANELLI, 1993).

\section{COMUNS}

- SOLICITAR QUE ESCLAREÇA TERMOS

Durante a comunicação enfermeira-paciente, o paciente pode utilizar termos comuns ao seu linguajar 
de difícil compreensão, que dão margem a várias interpretações. Quando isso acontece é necessário que o enfermeiro peça para esclarecer qual a significação, para ele do termo ou frase usada (STEFANELLI, 1993).

Nas entrevistas, os pacientes referiram essa técnica, manifesta nos textos a seguir:

\section{"Agora tinha coisas que eu perguntava e ela não entendia, e eu tinha que repetir e explicar o que ela não entendia." (Sujeito 01). "Quando ela não me entendia pedia explicando as coisas. "(Sujeito 06). \\ "Na conversa tinha hora que eu explicava as coisas para ela entender o que eu tava dizendo."(Sujeito 08)}

Nos depoimentos, encontramos o emprego dessa técnica pelo enfermeiro como forma de ajudar a esclarecer as idéias transmitidas pelo paciente. A solicitação ao paciente sobre o esclarecimento dos termos faz-se necessária, pois, só assim o profissional terá o real entendimento da mensagem transmitida. Nesse sentido, SILVA (1996) afirma que devemos questionar, sem constrangimento, o significado de um termo desconhecido ou sobre o qual não temos certeza. Às vezes, não conseguimos identificar os sentimentos ou compreender o sentido das palavras de algumas pessoas. Neste caso, é necessário o esclarecimento que ajuda a indicar ao paciente que o enfermeiro está tentando compreendê-lo.

No grupo de validação, as técnicas que são utilizadas para verificar se a compreensão da mensagem emitida está correta, devem ser utilizadas porque as mensagens emitidas podem apresentar vários significados para as pessoas envolvidas no processo terapêutico (STEFANELLI, 1993). Nesse grupo são encontradas três técnicas: repetir a mensagem do paciente, pedir ao paciente para repetir o que foi dito e sumarizar o conteúdo. Nenhuma dessas técnicas foi encontrada nos depoimentos dos pacientes.

Os enfermeiros que trabalham no CTI, ambiente de estresse constante, gastam a maior parte do seu tempo para manusear a tecnologia utilizada no tratamento dos indivíduos, o que muitas vezes impede que o enfermeiro chegue perto do paciente para validar as mensagens verbais e não-verbais emitidas pelo paciente. Nesse contexto STEFANELLI (1993) argumenta que quando não validamos a mensagem do paciente corremos o risco de agir embasada em nossos próprios valores, crenças ou interpretações errôneas.

Percebemos que as técnicas de comunicação terapêutica são meios que auxiliam a aproximação e o desenvolvimento de um relacionamento empático, ajudam à enfermeira descobrir sentimentos dos pacientes, bem como, no alivio da insegurança e do desconforto gerados pelo ambiente do CTI. Tais técnicas não devem ser usadas indistintamente, mas, de maneira individualizada.

Nesta análise, percebemos, também, que os enfermeiros utilizam com maior freqüência às técnicas relacionadas ao grupo de expressão. Isso pode ser explicado pelo fato das técnicas serem utilizadas para haver uma aproximação com o paciente que está em um ambiente que o assusta, e, em uma situação de estresse, sendo as técnicas de expressão uma forma de ajudar à adaptação.

As técnicas de clarificação foram observadas com menor freqüência, ao que se pode atribuir o fato de muitos profissionais não se preocuparem em tornar claro o conteúdo da mensagem que é transmitida pelo paciente. Os enfermeiros devem ter consciência da importância desta técnica, para o relacionamento terapêutico, pois ela ajuda a tornar mais explicito o conteúdo da mensagem emitida pelo paciente.

No que diz respeito às técnicas de validação, elas não foram encontradas nos depoimentos dos pacientes. Isso significa que os enfermeiros, muitas vezes, não validam a mensagem. Contudo, deveria a validação ser usada tanto quanto as demais técnicas, pois, possibilita à enfermeira interpretar se a mensagem tem o mesmo significado para ambos.

\section{CONSIDERAÇÕES FINAIS}

O desenvolvimento do presente estudo teve por fundamento o intuito de pesquisar sobre comunicação terapêutica, especificamente, abordar as técnicas nos aspectos conceituais e suas implicações para assistência de enfermagem. Constatei a importância e a complexidade do tema, ao considerar que a comunicação representa a base e o fundamento para as relações enfermeira-paciente, constituindo, dessa maneira, um instrumento básico para a enfermagem, em especial, para o enfermeiro no desenvolvimento de suas funções assistências.

$\mathrm{Na}$ realização do estudo, evidenciamos que os enfermeiros utilizam com maior freqüência às técnicas relacionadas ao grupo de expressão - ouvir reflexivamente; uso terapêutico do humor; verbalizar aceitação; usar terapeuticamente o silêncio; fazer perguntas; devolver a pergunta feita; usar frases descritivas; seguidas das técnicas de clarificação solicitar que esclareça termos comuns; estimular comparação. No que diz respeito às técnicas de validação, estas não foram encontradas nos discursos dos pacientes.

Os resultados da pesquisa mostram a importância da utilização das técnicas de comunicação terapêutica no estabelecimento do relacionamento terapêutico no CTI, considerado ambiente gerador de sentimentos como medo, tristeza, ansiedade, e como parte integrante da assistência, para assim prestarmos cuidados de qualidade mais próxima da integralidade da assistência, visando à recuperação do paciente.

Trabalhar em um ambiente estressante, como em um CTI, onde os pacientes estão em situações de risco - que permite uma rápida evolução do seu quadro clínico, tanto para a recuperação da saúde como para o aprofundamento do processo patológico - faz com que, muitas vezes, os enfermeiros não utilizem os recursos da comunicação como processo terapêutico. Desse modo, perde-se a oportunidade de se contribuir no sentido de uma aproximação da assistência 
hospitalar com os princípios do Sistema de Saúde da atualidade, o SUS, que defende a integralidade da assistência, ao mesmo tempo em que se promove a recuperação do paciente.

Para alcançar uma comunicação satisfatória e prestarmos cuidado humanizado, é preciso que o profissional que trabalhe no CTI deseje envolver-se e acredite que sua presença é tão importante quanto à realização de procedimentos técnicos, já que nem sempre os conhecimentos técnicos objetivos funcionam tão bem diante de situações de estresse como os conhecimentos subjetivos que se revelam na comunicação terapêutica. Assim sendo, é preciso reconhecer que, ficar ao lado do paciente para ouvi-lo é uma ação terapêutica e determinante no processo de recuperação da saúde.

Esperamos com este estudo contribuir para que os profissionais reflitam sobre a importância da utilização das técnicas de comunicação terapêutica na relação de assistência, quando o paciente precisa de auxilio e segurança, necessidades essências a serem consideradas para uma assistência de enfermagem humanizada visando 0 ser humano na sua individualidade e integralidade psicológica, social e espiritual.

\section{REFERÊNCIAS BIBLIOGRÁFICAS}

ATKINSON, L. D.; MURRAY, M.E. Fundamentos de Enfermagem: introdução ao processo de enfermagem. Rio de Janeiro: Guanabara Koogan, 1989.

BARCELLOS, V. R.; CAMPONOGARA, S. O uso da comunicação não-verbal no cuidado ao paciente cardiopata: percepções da equipe de enfermagem. In: COSTENARO, R. G. S. Cuidando em enfermagem: pesquisas e reflexões. Santa Maria:UNIFRA, 2001. 232p. p.53-72.

BITTES JÚNIOR, A; MATHEUS, M. C. Comunicação. In: CIANCIARULLO, T. I. Instrumentos básicos para o cuidar: um desafio para a qualidade da assistência. São Paulo: Atheneu, 1996. Cap. 6, p. 61-73.
DOBRO, E. R. H. et al. A percepção da realidade associada a uma situação hospitalar e a sua influência na comunicação interpessoal. Rev. ESc. Enf. USP, São Paulo, v.32, n.3, p. 255-261, 1998.

DU GAS, B. W. Enfermagem prática. Rio de Janeiro: Guanabara, 1989.

GATTÁS, M. L. B. Relacionamento interpessoal enfermeira-paciente. Rev. Paul. Enf., São Paulo, v. 4, n. 2, p. 12-18, 1984.

HUDAK, C. M.; GALLO, B.M. Efeitos da unidade de terapia intensiva sobre o enfermeiro. In: HUDAK, C. M.; GALLO, B.M.Cuidados intensivos de enfermagem: uma abordagem holística. 6 ed. Rio de Janeiro: Guanabara Koogan, 1997.

KRON, T.; GRAY, A. Administração dos cuidados de enfermagem ao paciente - Colocando em ações as habilidades de liderança. Rio de Janeiro: Interlivros, 1994.

NEGRINI, M. R.; RODRIGUES, A. R. F. Relacionamento terapêutico enfermeiro paciente junto a mulheres mastectomizadas. Revista o Mundo da Saúde, v. 24, n. 4, p. 16-22, 2000.

POTTER, P. A.; PERRY, A.G. Fundamentos de enfermagem: Conceitos, processo e prática. Ed. Rio de Janeiro: Guanabara Koogan, 2002.

SANTOS, N. R.; LEMES, M. D. A percepção e os sentimentos do paciente de familiares na UTI. Revista Estudos Vida e Saúde. v. 28, n. 6, p. 09-15, 2001.

SILVA, M. J. P. Comunicação tem remédio: a comunicação nas relações interpessoais em saúde. São Paulo: Editora Gente, 1996.

SINNO, M. Comunicação enfermeiro-cliente. Rev. Bras. de Enf., v. 40, n. 2/3, p. 09-15, 1987.

SMELTZER, S. C.; BARE, B. G. Brunner \& Suddarth Tratado de Enfermagem Médico-Cirúrgica. 8. ed. Rio de Janeiro: Guanabara Koogan, v.1, 2000.

STEFANELLI, M. C. Comunicação com paciente teoria e ensino. São Paulo: Robe editorial, 1993.

STUART, G. W.; LARAIA, M.T. Enfermagem Psiquiátrica. 4. Ed. Rio de Janeiro: Reichman e Affonso, 2002.

*Trabalho extraído do Trabalho de Conclusão do Curso de Graduação em Enfermagem da Universidade Federal da Paraíba de OLIVEIRA (2005).

${ }^{1}$ Enfermeira. Graduada pela Universidade Federal da Paraíba, João Pessoa.

${ }^{2}$ Enfermeira. Doutora em Enfermagem. Professora do Departamento de Enfermagem em Saúde Pública e Psiquiatria do Centro de Ciências da Saúde da Universidade Federal da Paraíba. Pesquisadora CNPq. E-mail: miriam@ccs.ufpb.br

${ }^{3}$ Enfermeira. Doutora em Enfermagem, Professora do Departamento de Enfermagem em Saúde Pública e Psiquiatria do Centro de Ciências da Saúde da Universidade Federal da Paraíba. E-mail: ana@jpa.neoline.com.br

${ }^{4}$ Enfermeira. Doutora em Enfermagem. Professora do Departamento de Enfermagem em Saúde Pública e Psiquiatria do Centro de Ciências da Saúde da Universidade Federal da Paraíba. E-mail: mafilha@yahoo.com.br 